Article

\title{
Experimental Investigation of the Macroscopic Behavior and Microstructure Property Evolution of Hardened Cement Consolidated Tailings
}

\author{
Xiang Sun and Yunbing Hou * \\ School of Energy and Mining Engineering, China University of Mining and Technology, Beijing 100083, China; \\ sunxiang90816@163.com \\ * Correspondence: hyb@cumtb.edu.cn
}

Received: 20 November 2019; Accepted: 16 December 2019; Published: 19 December 2019

\begin{abstract}
Surface cement consolidated tailings disposal has recently been proposed to manage tailings in the modern mining industry because it can reduce or eliminate the disadvantages of traditional tailings storage. In this study, the evolution of the macro performance and microstructure characteristics of cement consolidated tailing samples during the curing period were determined by unconfined compressive strength tests, permeability tests, scanning electron microscopy (SEM) observations, and mercury intrusion porosimetry (MIP) tests, respectively. The results show that the curing time notably affected the macro performance and microstructural properties of the hardened cement consolidated tailings samples. As the curing age increases, the compressive strength increases nonlinearly and the growth rate decreases; the permeability decreases rapidly first, then gradually stabilizes, and finally reaches a stable value; the morphology of the hydration products and microstructures continues to evolve with the hydration process; the total pore volume decreases slightly, whereas the critical pore size decreases significantly. The proportion of the pore volume in different pore size ranges can also be affected by the curing age, which results in a large pore $(>200 \mathrm{~nm})$ decrease, and the small pores $(<200 \mathrm{~nm})$ increased. In this process, the filling effect plays a major role.
\end{abstract}

Keywords: cement consolidated tailings; curing age; compressive strength; permeability; microstructure; evolution

\section{Introduction}

The mining industry is a dominant industry for national economic development in many countries worldwide and provides an important material basis for the survival and development of human society [1]. However, a large amount of mine solid wastes such as waste rock and tailings are also generated in the production process [2], among which tailings account for approximately $80 \%$ of the total amount of waste. According to the relevant statistics [3], the total amount of stockpiles of tailings in China has exceeded 20 billion tons, and the annual emissions have reached more than 1.6 billion tons in recent years. With the continuous improvement of the technical level of mineral processing, the optional grade of ore is decreasing, further increasing the emissions of tailings [4,5]. If the tailings cannot be disposed of and managed reasonably, it will cause land occupation, environmental pollution, and geological hazards such as landslides and mudslides, which will have a lasting and harmful impact on the social economy and environment [6]. At the same time, improper disposal of tailings also restricts the green, safe, efficient and sustainable development of modern mines [7].

At present, except for approximately $11 \%$ of tailings used for underground mine backfilling $[8,9]$, most tailings are stored in the form of a tailings slurry in traditional tailings ponds [10,11]. Because 
the concentration of tailings discharged into the tailings pond is low (20-40 wt $\%$ ), the water content is high, the height of the tailing dam is large, and the safety factor of the tailings pond is low, which produces a potential high potential energy hazard. It is difficult to maintain the physical integrity and stability of the tailings dam for a long time, and the maintenance cost is high, which is a further challenge [7,12,13]. Especially in heavy rains, floods, typhoon seasons, and earthquake-prone areas, accidents are easily caused such as dam breaks, landslides and seepage in tailings the ponds [14,15], causing great threats and damage to people's lives and property. In September 2008, the dam of an iron ore tailings dam in Shanxi Province collapsed, resulting in 277 deaths, four people missing, and 33 injured, while direct economic losses reached 96.192 million yuan [16]; in November 2015, the Samarco iron ore tailings dam accident in Brazil killed 19 people, and caused the leakage of six million cubic meters of residual waste, polluting $650 \mathrm{~km}$ of rivers and remitting tailings into the Atlantic Ocean, causing the most serious environmental disaster in Brazil's history [15,17]; in 2019, the tailings dam of the Córrego do Feijão mine in Brazil leaked and collapsed, 235 people were killed and 35 people were missing, and the accident caused serious pollution to the surrounding ecology.

At present, with increasingly stringent environmental regulations [18], government departments have attached great importance to safety in the production industry. The modern mining industry has been forced to explore safe and reliable tailings surface treatment methods to reduce or eliminate the drawbacks of traditional tailings storage $[19,20]$, to more effectively meet environmental and regulatory requirements [7]. Tailings consolidation surface disposal is an emerging tailings surface treatment technology with great development potential [21]. The technology dehydrates the tailings slurry discharged from the mineral processing plant by using concentration or filtration equipment, and then uniformly mixes the dewatered tailings, hydraulic cementing materials (such as ordinary Portland cement, fly ash, blast furnace slag or their mixtures) [22,23] and water in a certain proportion. Transported by a belt conveyor or truck [7], the mixtures are stacked at a designated location. Artificial hardening composite materials with certain engineering characteristics are formed due to condensation and hardening during the hydration of the cementation agents. The tailings consolidation disposal technology is beneficial for the recycling of ore dressing water [24], which can reduce the water content in the tailings, improve the safety factor of the consolidated pile, reduce or eliminate the large construction cost of the tailings dam, and facilitate the timely storage of the tailings and gradual rehabilitation of the site. This technology has advantageous safety, environmental protection, and economic benefits.

Due to the short amount of time that this technology has been proposed and applied, previous studies have mostly focused on dehydration, cementing materials and economic costs. However, the lack of systematic research on the engineering characteristics of the post-stacked consolidated bodies has led to a lack of a comprehensive understanding of the technology. To some extent, it limits the application and promotion of this technology. According to the concept and advantages of this technology, it can be seen that the tailings will be consolidated into an artificial pile when they are placed in the designated position. First, the formed pile should have a certain stability; that is, the consolidated body must have sufficient mechanical strength to ensure structural safety. Second, whether the consolidated pile can exert its engineering characteristics for a long time depends on its durability. Durability mainly includes frost resistance and erosion resistance. Although their mechanisms and manifestations are different, they are all determined by the impermeability of the consolidated body. Finally, the consolidated body is required to be environmentally friendly. Tailings containing sulfide minerals in contact with water and oxygen can produce acid mine drainage (AMD), which can lead to the acidification of the surrounding water and land resources, as well as cause the release and migration of heavy metal ions. This requires the consolidated body to have a low permeability to prevent the oxidation of sulfide minerals $[25,26]$. In summary, strength and permeability are two key parameters for assessing the performance of the consolidated body. The consolidated body is an engineering material with certain engineering properties due to the coagulation and hardening of the added cementation material and can be regarded as a cement-based material with a high water-cement 
ratio and tailings as the aggregates. According to the characteristics of cement-based materials, its macro performance [27] is determined by its microstructure characteristics, and the microscopic pore structure is one of its important properties [28,29]. As the hydration reaction progresses, it evolves and affects the macroscopic properties such as strength [30-33] and permeability [34-36].

However, in the past, the study of consolidated bodies has mainly focused on the strength as the index to measure its macro performance, ignored the study of consolidation permeability, and rarely reported the systematic study of the macro performance of the consolidated bodies combined with the microstructure evolution of the consolidated bodies. To study the engineering properties of the consolidated body more comprehensively, this paper studies the evolution law of the strength and permeability of the consolidation body with respect to the curing age through unconfined compressive strength (UCS) and permeability tests from a macroscopic perspective. Through scanning electron microscopy (SEM) and mercury intrusion porosimetry (MIP) tests, the hydration process and the evolution of the microscopic pore structure characteristics of the consolidation body were analyzed from the microscopic perspective. By studying the consolidation body from the macroscopic and microscopic perspectives, this research provides a basis for further exploring the relationship between the macroscopic properties and the microscopic pore structure, and reveals the mechanism of the macroscopic performance of the consolidator. Furthermore, the engineering properties of the consolidated body could be improved by optimizing the microstructure.

\section{Materials and Methods}

\subsection{Materials}

The materials used to prepare the consolidated test samples mainly include tailings, cement, and mixed water.

\subsubsection{Tailings}

The Lilou-Wuji iron mine (China Minmetals Mining Company), located in Lu'an, Anhui Province, China, provided all the tailings for this study. Tailings were collected from the ore processing plant and stored in barrels. After transfer to the laboratory, the tailings were air-dried, sieved and homogenized before the experiment. The basic physical properties of the tailings are presented in Table 1, while the chemical composition measured by XRF methods (AXIOS ${ }^{\mathrm{mAX}}$, PANalytical, Almelo, The Netherlands) is presented in Table 2 .

Table 1. Basic physical properties of the tailings.

\begin{tabular}{cccccccc}
\hline $\begin{array}{c}\text { Natural Moisture } \\
\text { Content }(\%)\end{array}$ & $\begin{array}{c}\text { Density } \\
\left(\mathrm{g} / \mathrm{cm}^{3}\right)\end{array}$ & $\begin{array}{c}\text { Specific } \\
\text { Gravity, Gs }\end{array}$ & $\begin{array}{c}\text { Porosity } \\
(\text { vol.\%) }\end{array}$ & $\begin{array}{c}\text { Porosity } \\
\text { Ratio }\end{array}$ & $\begin{array}{c}\text { Natural Repose } \\
\text { Angle }\left({ }^{\circ}\right)\end{array}$ & $\begin{array}{c}\text { Liquid Limited } \\
(\%)\end{array}$ & $\begin{array}{c}\text { Plastic Limited } \\
(\%)\end{array}$ \\
\hline 61.5 & 1.741 & 2.94 & 34.66 & 1.68 & 39 & 21 & 7 \\
\hline
\end{tabular}

Table 2. Chemical compositions of the tailings (unit: wt.\%).

\begin{tabular}{ccccccccccc}
\hline $\mathrm{SiO}_{2}$ & $\mathrm{Fe}_{2} \mathrm{O}_{3}$ & $\mathrm{Al}_{2} \mathrm{O}_{3}$ & $\mathrm{CaO}$ & $\mathbf{M g O}$ & $\mathrm{K}_{\mathbf{2}} \mathrm{O}$ & $\mathrm{Na}_{2} \mathrm{O}$ & $\mathrm{TiO}_{2}$ & $\mathbf{P}_{\mathbf{2}} \mathrm{O}_{5}$ & $\mathrm{SO}_{3}$ & $\mathbf{M n O}$ \\
\hline 82.052 & 8.003 & 3.849 & 2.461 & 2.143 & 0.700 & 0.179 & 0.106 & 0.076 & 0.076 & 0.021 \\
\hline
\end{tabular}

The particle size distribution of the tailings was measured using a laser particle size analyzer (Winner 2308, Winner Particle, Jinan, China) according to the standard GB/T19077-2016, as shown in Figure 1. The particle size distribution results indicate that the particle size of the tailings is mainly concentrated from $20-300 \mu \mathrm{m}$, the particle size distribution is more discrete, there are less fine particles than coarse particles, and the natural grading is relatively discontinuous. The volume-specific surface area was $2790.114 \mathrm{~cm}^{2} / \mathrm{cm}^{3}$, and the nonuniformity coefficient $\left(\mathrm{Cu}=\mathrm{D}_{60} / \mathrm{D}_{10}\right)$ and coefficient of curvature $\left(C_{c}=d_{30}^{2} /\left(d_{60} / d_{10}\right)\right)$ were 8.94 and 1.62 , respectively, which indicates that the tailings have excellent gradation and good engineering properties. 


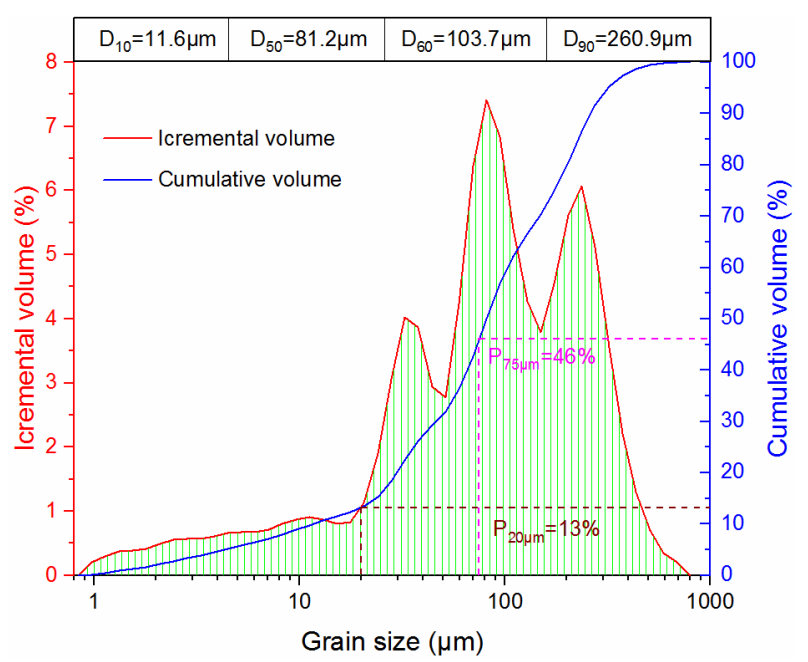

Figure 1. Particle size distribution of the tailings.

\subsubsection{Cement}

Ordinary Portland cement (P.O42.5) was used in this study; its main physical properties and chemical compositions are shown in Tables 3 and 4, respectively. Tables 3 and 4 show that the cement properties and composition indicators used in this test are in line with the China cement standards GB 175-2007 [37].

Table 3. Main physical properties of the P.O42.5 Portland cement.

\begin{tabular}{|c|c|c|c|c|c|c|c|c|c|}
\hline \multirow{2}{*}{$\begin{array}{l}\text { Density } \\
\left(\mathrm{g} / \mathrm{cm}^{3}\right)\end{array}$} & \multirow{2}{*}{$\begin{array}{l}\text { Specific Surface } \\
\text { Area }\left(\mathrm{m}^{2} / \mathrm{kg}\right)\end{array}$} & \multirow{2}{*}{$\begin{array}{c}\text { Consistency } \\
(\%)\end{array}$} & \multirow{2}{*}{$\begin{array}{c}\text { Fineness } \\
(\%)\end{array}$} & \multicolumn{2}{|c|}{ Setting Time (min) } & \multicolumn{2}{|c|}{$\begin{array}{c}\text { Flexural } \\
\text { Strength (MPa) }\end{array}$} & \multicolumn{2}{|c|}{$\begin{array}{c}\text { Compressive Strength } \\
\text { (MPa) }\end{array}$} \\
\hline & & & & $\begin{array}{l}\text { Initial } \\
\text { Setting }\end{array}$ & $\begin{array}{c}\text { Final } \\
\text { Setting }\end{array}$ & $3 d$ & $28 d$ & $3 d$ & $28 d$ \\
\hline 3.16 & 352.95 & 26.7 & 2.35 & 159 & 235 & 5.9 & 8.3 & 26.2 & 50.2 \\
\hline
\end{tabular}

Table 4. Chemical composition of the P.O42.5 Portland (unit: wt.\%).

\begin{tabular}{ccccccccccc}
\hline $\mathrm{SiO}_{2}$ & $\mathrm{CaO}$ & $\mathrm{Al}_{2} \mathrm{O}_{\mathbf{3}}$ & $\mathrm{Fe}_{\mathbf{2}} \mathrm{O}_{3}$ & $\mathbf{M g O}$ & $\mathrm{SO}_{3}$ & $\mathrm{Na}_{2} \mathrm{O}$ & $\mathrm{K}_{\mathbf{2}} \mathrm{O}$ & $\mathbf{f}-\mathrm{CaO}$ & $\mathrm{TiO}_{2}$ & Loss \\
\hline 22.31 & 60.98 & 5.87 & 3.38 & 2.32 & 2.49 & 0.39 & 0.75 & 0.2 & 0.58 & 2.51 \\
\hline
\end{tabular}

\subsubsection{Mixing Water}

The mixing water used for preparing the tailings consolidated body specimens was urban tap water.

\subsection{Sample Preparation and Mix Design}

The required tailings, cement and water were weighed according to the experimental design. The tailings and cement were poured into the mixing tank and dry mixed for $1 \mathrm{~min}$ with an agitator to mix them evenly. Then, water was added and stirred for $6 \mathrm{~min}$ to obtain a homogeneous mixture, thus mimicking on-site preparation. The stirred mixture was cast into a cylindrical plastic mold that is detachable at both ends, with a height of $100 \mathrm{~mm}$ and a diameter of $50 \mathrm{~mm}$. Before pouring, a layer of engine oil was evenly applied to the inner wall of the mold for subsequent demolding. The consistency and reliability of the final preparation of the sample was ensured by vibrating the mixture in the mold. At least three parallel samples were prepared for each set to ensure the repeatability of the subsequent test results. All the samples were demolded after a $24 \mathrm{~h}$ curing time, and further curing was continued in a standard constant temperature and humidity curing chamber (YH-40B, Hebei, China) at a temperature of $20 \pm 2{ }^{\circ} \mathrm{C}$ and relative humidity of $90 \%$ for the specified curing ages. 
In this study, five mix design tailings consolidated body samples were prepared and cured for 3, 7, 14, 28, and 60 days. The details of the mix design adopted for the tested samples are presented in Table 5. Since the binder used in this study is cement, the prepared samples called cement consolidated tailings samples (CCT). In the label of each mix, the number indicates the proportion of cement. In particular, the cement content of $0 \%$ (i.e., CCT-0) was used to measure the strength and permeability at 0 days of curing.

Table 5. Mix proportions of tested samples.

\begin{tabular}{ccc}
\hline Mix Label & Cement Content (wt.\%) & Solid Mass Concentration (wt.\%) \\
\hline CCT-0 & 0 & 78 \\
CCT-4 & 4 & 78 \\
CCT-6 & 6 & 78 \\
CCT-8 & 8 & 78 \\
CCT-10 & 10 & 78 \\
\hline
\end{tabular}

\subsection{Experimental Methods}

\subsubsection{Unconfined Compressive Strength Tests}

UCS is an index that is frequently used to evaluate the mechanical strength characteristics of materials [38] because the test is fast, simple and reliable. Compressive strength measurements were performed using a computer-controlled mechanical press (WDW-100E, Jinan, China) with a normal loading capacity of $100 \mathrm{kN}$. The compression test was displacement-controlled at a loading rate of $0.5 \mathrm{~mm} / \mathrm{min}$ in accordance with the standard ASTM C109.

The UCS of the samples listed in Table 5 were determined using at least three cylindrical specimens for each mix type at each specified curing age to ensure the repeatability of the experimental test results. The average value of each group of the test results is taken as the final UCS value.

\subsubsection{Permeability Measurements}

The permeability coefficient, $\mathrm{k}$, also known as the hydraulic conductivity, is an important physical parameter for characterizing the permeability of porous media materials. Hydraulic conductivity tests were conducted using an environmental geotechnical flexible wall triaxial permeameter (PN3230M, GEOEQUIP, Chicago, IL, USA) in accordance with ASTM D5084-00. Each test was performed at least twice to ensure the repeatability of the obtained results, and the average value was considered as the permeability coefficient of the sample.

\subsubsection{Scanning Electronic Microscopy}

To observe the change in the hydration products and microstructure morphology of the CCT sample at different curing times, a series of observations were performed using scanning electron microscopy (JSM-7800F, JEOL, Tokyo, Japan). The operating conditions include a current emission of approximately $110 \mu \mathrm{A}$, an accelerating voltage of $5 \mathrm{keV}$, a working distance of $15 \mathrm{~mm}$, and a lowered pressure of $25 \mathrm{~Pa}$ to avoid the effects of harmful electrical charge on the image quality. To improve the quality of the acquired image, all samples were vacuum coated with a layer of gold to produce electrical conductivity and prevent electric charge accumulation on the specimens $[39,40]$. The images were collected under the secondary electron (SE) mode, with a gray level that depends on the surface topography of the observed areas. The image acquisition was performed at two magnifications; $500 \times$ and 5000×. The SEM analysis procedure is explained elsewhere [41,42].

\subsubsection{Mercury Intrusion Porosimetry}

Mercury intrusion porosimetry (MIP) is a commonly used method to evaluate the microscopic pore structure of cement-based materials [43]. It is considered to be the most suitable method because 
a wide range of pore size distribution (PSD) varying from $0.001 \mu \mathrm{m}$ to $1000 \mu \mathrm{m}$ can be determined [44], and it is an effective tool to detect pore filling caused by cementation [45].

In the MIP test, the specified test sample is weighed and placed into a chamber. The chamber is then filled with mercury. The mercury is forced into the pores of the sample, as the pressure applied to the mercury is gradually increased. The volume of mercury intruded into the sample is monitored at each pressure increment. To fill the pore spaces of diameter $d$, a nonreactive and nonwetting liquid is applied as a pressure $p$ that is inversely proportional to the diameter of the pore [46]. The corresponding pore size is calculated by the Washburn equation as shown below [47]:

$$
\mathrm{d}=-\frac{4 \gamma \cos \theta}{\mathrm{p}}
$$

where $\mathrm{d}$ is the apparent pore diameter, $\gamma$ is the surface tension of the mercury, and $\theta$ is the contact angle between the mercury and the pore wall.

Like most techniques, MIP techniques have certain limitations during their application [28]. However, the MIP technique is still considered an appropriate method and an invaluable tool for comparing the pore structure characteristics of cement-based materials [48]. In several studies [49], the estimated pore structure has been shown to be reliable for similar testing methods and the conditioning of samples.

In this study, the pore structure evolution of the CCT samples was evaluated using an MIP apparatus (Auto Pore IV 9510, Micromeritics, Norcross, GA, USA) in accordance with the standard GB/T 21650.1-2008 [50]. The mercury intrusion pressure varied from 0.1 to 60,000 psi (414 MPa), which, according to theoretical analysis, this pressure is capable of measuring a pore sizes range of $0.003-1100 \mu \mathrm{m}$. The weights of the samples were approximately $3 \mathrm{~g}$. The values for the contact angle, surface tension, and density of the mercury were set to $140^{\circ}, 0.480 \mathrm{~N} / \mathrm{m}$, and $13.5335 \mathrm{~g} / \mathrm{L}$, respectively, in this study.

\subsubsection{Sample Drying Pretreatment}

Prior to SEM and MIP tests, hydration must be stopped and the samples must be dried. After the UCS test, one cubic specimen with a length of $25 \mathrm{~mm}$ was cut from the center part of each CCT sample. The specimens were then frozen by immersion in liquid nitrogen $\left(-195^{\circ} \mathrm{C}\right)$ for $5 \mathrm{~min}$ to stop the hydration process [51], and the specimens were subsequently dried in a freeze desiccator controlled at a constant vacuum pressure [52] of approximately $30 \mathrm{mmHg}(4 \mathrm{kPa})$ for $24 \mathrm{~h}$ to eliminate any residual moisture. This method was used to minimize the damage caused to the pore structure of the CCT sample [53].

\section{Results and Discussion}

\subsection{Compressive Strength Evolution of CCT Samples with Curing Age}

Figure 2 shows the relationship between the UCS and curing age of the CCT samples listed in Table 5. As shown in Figure 2, in general, all samples had comparable strength evolution characteristics regardless of the cement content. That is, under different cement contents, the UCS of the CCT samples increases with increasing curing age. This behavior can be explained by the fact that the cement hydration reaction process increased with increasing. This resulted in an increase in the amount of cement hydration products. These hydration products fill the pores between the tailings particles in the consolidated body, which produces a denser texture structure of the CCT densifying, the hydration products have a certain cementation effect, and the tailing particles are bonded together, resulting in the increase of the UCS of CCT samples. This indicates that the structural stability of the consolidated pile gradually increases as the curing age increases. 


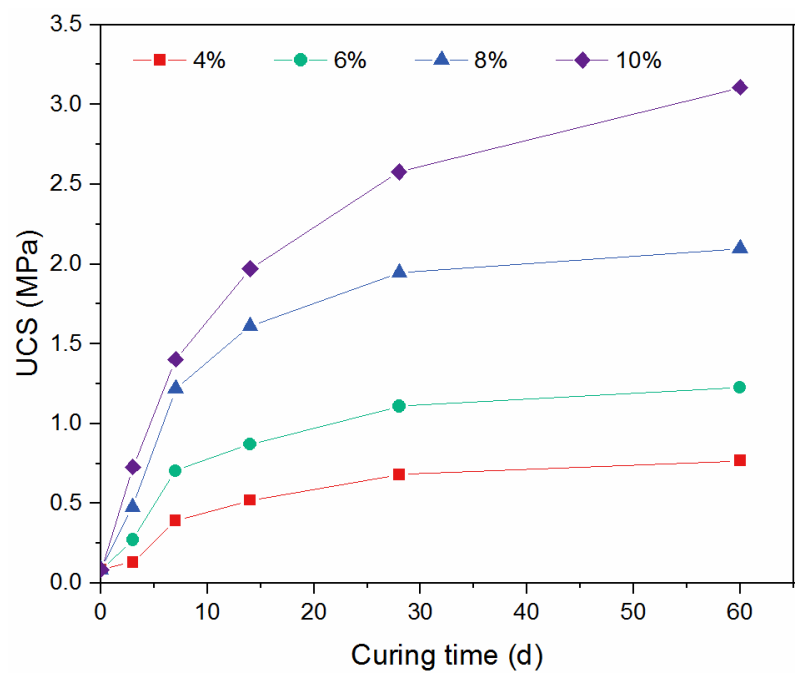

Figure 2. Unconfined compressive strength (UCS) evolution of called cement consolidated tailings (CCT) samples with different cement content yields from 3 to 60 days during the curing age.

Figure 2 also shows that the strength evolution has a nonlinear relationship with increasing curing age. Specifically, the growth rate of the UCS of all CCT samples listed in Table 5 decreased with increasing curing age. The growth rate was the highest at 3 days and 7 days, followed by 14 days and 28 days, with 28 days to 60 days showing an almost flat rate of increase. That is, the UCS tends to be stable during the late curing age. This is attributed to the fact that the hydration reaction rate of cement is faster at an early curing age, and as the curing age increases, the hydration rate gradually slows down and the UCS tends to stabilize. This is consistent with the acceleration, deceleration and stability phases of the cement hydration reaction process. Therefore, in engineering applications, the 28day strength is generally used as the final strength of the consolidated body. It should be noted that for CCT-10 samples, curing ages from 20 to 60 days still produce a certain strength increase. This is likely because when the cement content exceeds a certain value, after 28 days of curing, there is still a certain amount of cement that is not fully hydrated.

For all CCT samples listed in Table 5, the relationship of the UCS after 7 and 28 days of curing can be expressed as $q_{7}=(0.54 \sim 0.64) q_{28}$. This expression indicates that the UCS of the CCT samples after a curing period of 7 days is slightly greater than half that of the USC measured after 28 days of curing. Similar results were observed for cement-stabilized marine clay in a previous study [40]. The authors found that the relationship can be expressed as $q_{7}=0.58 q_{28}$.

Based on Abrams' law [54] and experimental data obtained from this study, a time-dependent strength prediction equation (Table 6) for the CCT samples was proposed. In a semilogarithmic coordinate system, a linear relationship is found between $f_{t} / f_{28}$ and curing age, which can be used to predict the strength evolution.

where $t$ is the curing time, day, $f_{t}$ is the UCS after $t$ days of curing.

Table 6. The equation and R-squared values of four types of CCT samples.

\begin{tabular}{ccc}
\hline Samples & Equation & R-Squared Value \\
\hline CST-4 & $\frac{f_{t}}{f_{28}}=0.545+2.765 \ln t$ & $R^{2}=0.9995$ \\
CST-6 & $\frac{f_{t}}{f_{28}}=0.328+2.960 \ln t$ & $R^{2}=0.9958$ \\
CST-8 & $\frac{f_{t}}{f_{28}}=0.343+2.908 \ln t$ & $R^{2}=0.9904$ \\
CST-10 & $\frac{f_{t}}{f_{28}}=0.412+2.949 \ln t$ & $R^{2}=0.9766$ \\
\hline
\end{tabular}




\subsection{Permeability Evolution with Curing Age}

The permeability evolution with respect to the curing age of CCT-8 samples is illustrated in Figure 3. From this figure, it can be seen that the general trend of the curve shows that the permeability of the CCT- 8 samples decreases with increasing curing time. After 60 days of curing, the permeability coefficient is reduced by an order of magnitude. The results are similar to a previous study on cement paste backfill $[55,56]$. The reason for the reduction is that as the hydration reaction continues, more hydration products are formed, and the aggregation of these hydration products densifies the pore structure of the CCT samples. The pore connectivity deteriorates, and the flow of water in the pore channels is hindered.

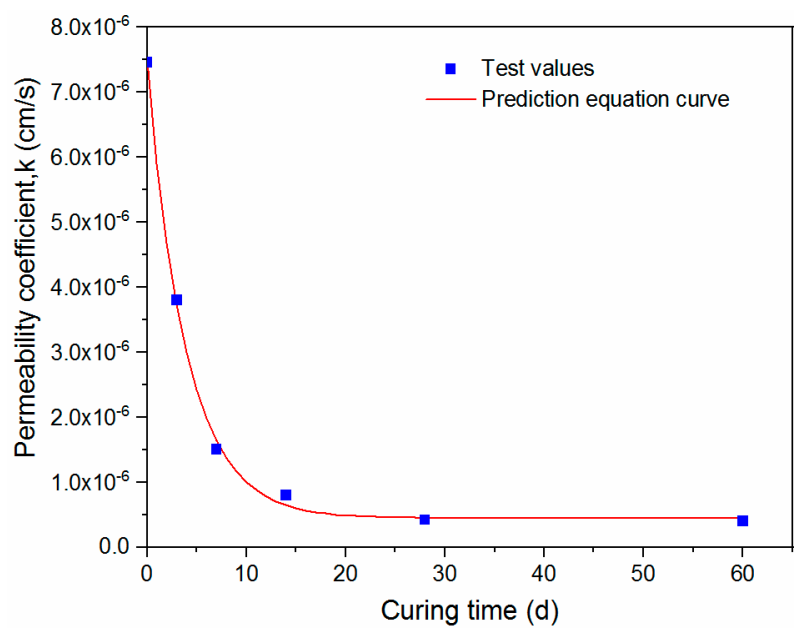

Figure 3. Permeability coefficient development of CCT-8 sample with respect to curing age.

Further analysis of the permeability evolution trend shows that the permeability coefficient decreases rapidly during the curing period of 0 to 7 days, gradually stabilized during the curing period of 7 to 28 days, and after 28 days of curing, the permeability coefficient basically reaches a stable value. Similar evolution trends were observed for cement paste backfill in a previous study [41]. This is likely because the hydration reaction rate of the cement is faster before 7 days of curing than that of the reaction rate after 7 days. The hydration products gradually fill the initial pores inside the CCT samples. The effect of this filling on the permeability of the CCT is mainly manifested in two aspects: (i) the hydration products completely fills the pores inside the CCT samples, causing the connected pores to be cut off, reducing the connectivity of the pore system; (ii) the large pores are partially filled by the hydration products, which makes the pore diameter smaller; that is, the pores are refined, resulting in a narrower flow path, reducing the fluidity of liquid inside the CCT samples. The superposition of these two actions leads to a rapid decrease in the permeability coefficient. Therefore, the filling and refinement of the initial pores inside the CCT sample by the hydration products is a major factor leading to the permeability evolution.

As the CCT sample rapidly reaches a low permeability, it can prevent and inhibit the oxidation of sulfur-containing minerals in the tailings to produce acid mine wastewater and the migration and exudation of heavy metal ions in a short time. Therefore, this process improves the environmental performance of the CCT sample, and at the same time, the low permeability can also enhance the erosion resistance of the CCT sample.

According to the experimental test results, a general regression equation describing the evolution of the CCT sample permeability with respect to the curing age is established. The exponential equation is:

$$
y=a \times e^{-b x}+c,
$$


where $a, b, c$ are fitting parameters, a and c are related to the initial permeability of the CCT sample, and $b$ is a constant, which can be seen as a proportionality constant related to the cement type, ratio and physical properties of the tailings. The regression coefficients from the experimental test are $\mathrm{a}=7.0177 \times 10^{-6}, \mathrm{~b}=-0.2536$, and $\mathrm{c}=4.4753 \times 10^{-7}$, with a coefficient of correlation of $\mathrm{R}=0.9993$.

\subsection{Micromorphology Evolution with Curing Age}

During the tailing consolidation process, the hydration process of the cement mainly includes the hydrolysis and the hydration reaction of the cement, which can be simply summarized as the dissolution of various mineral phases in the cement and the precipitation process of the hydration products [57].

Figure 4 is a microscopic topography of the CCT- 8 sample at 5000x. As the hydration reaction progresses, the minerals dissolved on the surface of the cement particles combine with water to generate a large amount of hydration products inside the CCT samples. The morphology of the hydration products is mainly composed of cementitious substances. The main components of the hydration products are hydrated calcium silicate $(\mathrm{C}-\mathrm{S}-\mathrm{H})$ gel, hexagonal plate calcium hydroxide $(\mathrm{CH})$ crystals, and columnar ettringite $(\mathrm{AFt})$ crystals. Among them, $\mathrm{C}-\mathrm{S}-\mathrm{H}$ is the main source of the consolidation strength.

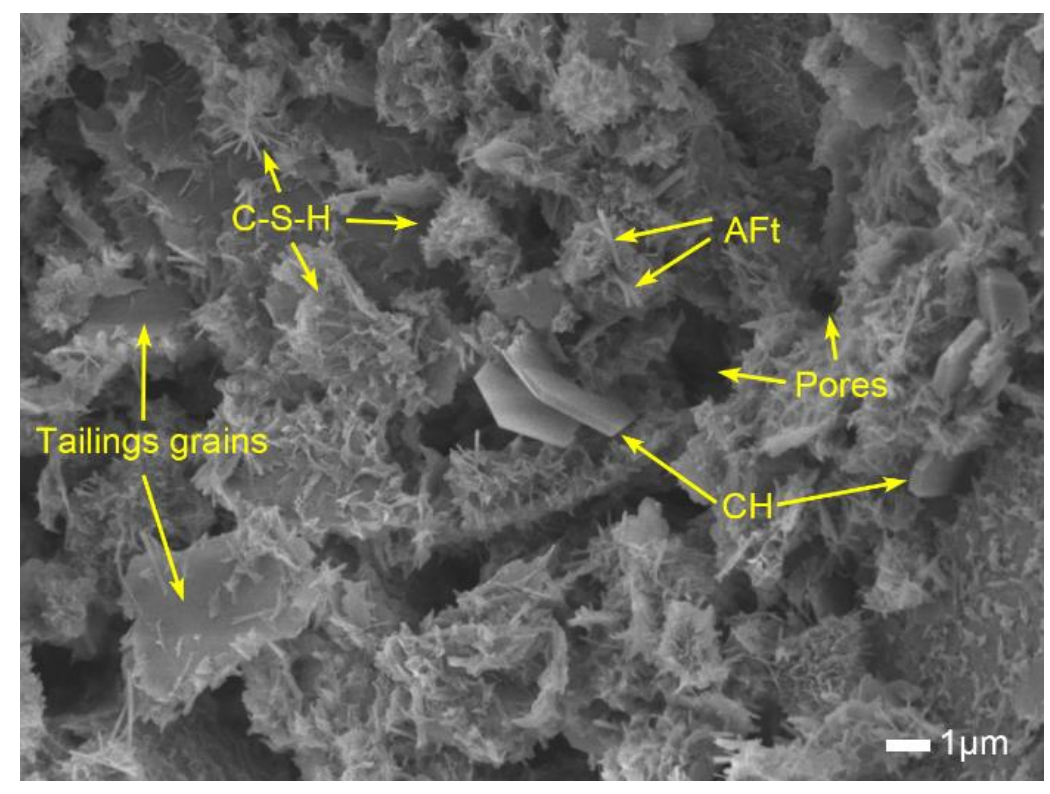

Figure 4. Scanning electron microscopy (SEM) image of the CCT-8 sample.

Figure 5 is a scanning electron microscope image of CCT-8 samples with two magnifications (500X and $5000 \times$ ) at curing ages of $3,7,14,28$, and 60 days. The label of each micrograph digital indicates the curing age and the character " $a$ " and " $b$ " represent a magnification of 500 $\times$ and $5000 \times$, respectively. The hydrated product crystal and microstructure morphology evolution of the CCT-8 sample was observed by high and low magnification scanning electron microscopy. 

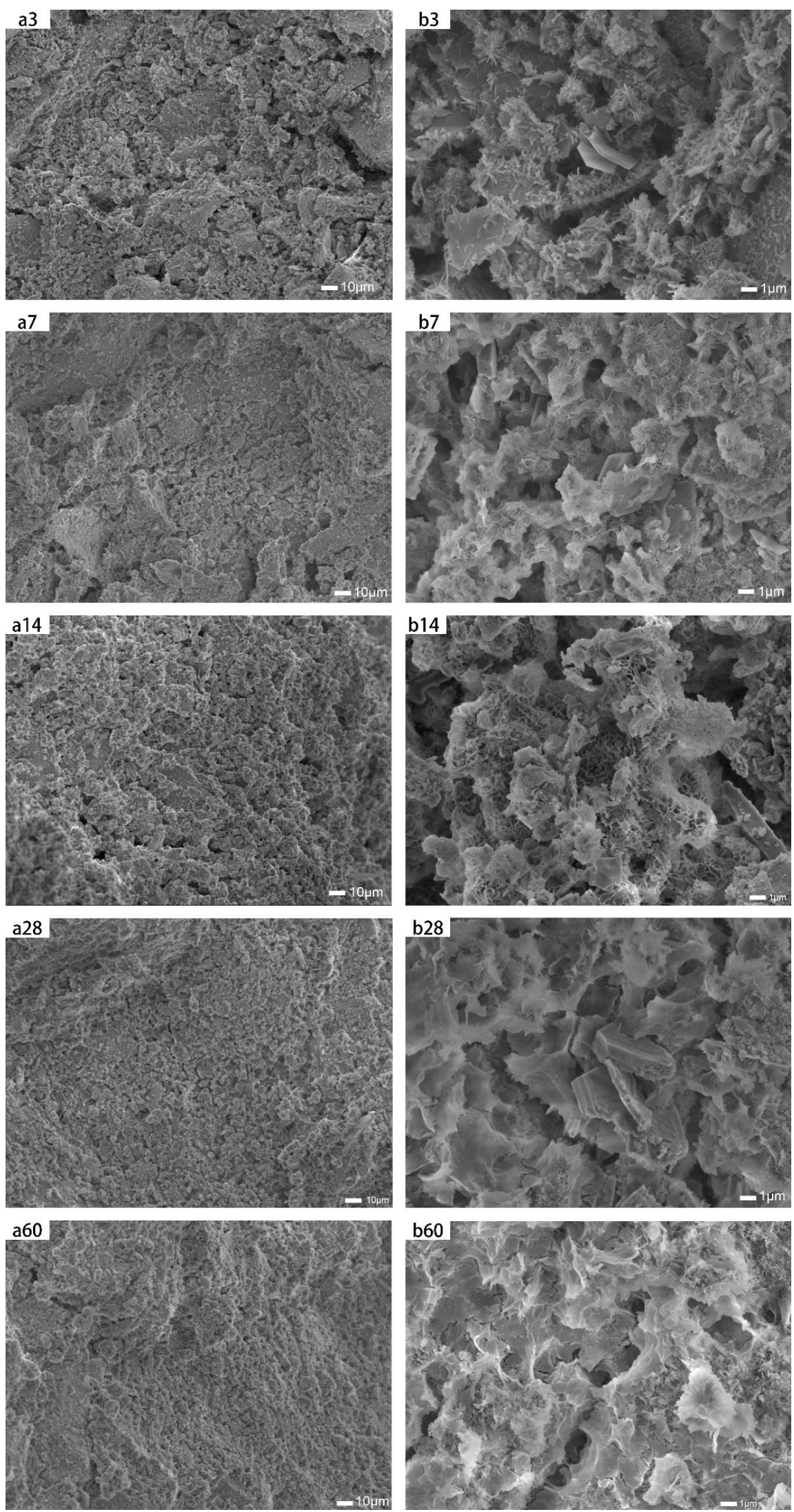

Figure 5. SEM images of the CCT- 8 samples at curing ages of $3,7,14,28$, and 60 days at different magnifications. Note: In the label of each micrograph "a" and " $b$ " represent a magnification of $500 x$ and $5000 \times$, and digital indicates the curing age. 
It can be seen from Figure 5 that as the curing age increases, the amount and crystal morphology of the hydration products and microstructure are all evaluated as the curing age increases. These hydration products accumulate and precipitate in the pores between the tailing particles, and then the hydration products coagulate and harden, resulting in a great change in the internal microstructure of the samples. It can be observed from Figure $5(\mathrm{a} 3, \mathrm{~b} 3)$ that a large amount of unhydrated cement particles adhere to the surface of the tailing particles. Only a small portion of the cement particles begin to hydrate, forming fine, discrete fibrous $\mathrm{C}-\mathrm{S}-\mathrm{H}$ and a small amount of calcium hydroxide and ettringite crystals. The pores between the tailing particles are large, and the outline is clear. Due to less hydration products, the crystallization is poor, and the filling between the pores and the cementation between the tailing particles is very weak. In Figure 5(a7,b7), as the number of fibrous C-S-H increases with an increase in the hydration reactions, they are interlaced to form a discontinuous, loose network structure, and a small amount of calcium hydroxide crystals are wrapped in the network structure. The hydrated product particles attached to the surface of the tailing particles increase, even though the amount of the hydrated product increases, but the increase is still relatively small and discrete. Cementation and filling effects are still not significant. In Figure 5(a14,b14), as the amount of hydration products increases further, the hydrated products gradually grow and accumulate, and some networked C-S-H crystals are gradually transformed into flocculated granules. The surface of the tailing particles are mostly covered, the cementation products form a connection, and the pores are filled, leading to a decrease in the pore size and number of pores, and the denseness of the consolidated body is increased. In Figure 5(a28,b28), the amount of hydration products in the form of flocculated particles is further increased, the volume of the gel particles becomes larger, the tailing particles are almost completely wrapped by the hydrated product gel, and a good connection between the particles is formed. The internal pores are obviously filled and refined, and the denseness of the consolidated body is significantly increased. At the curing age of 60 days, shown in Figure 5(a60,b60), the hydrated calcium silicate gel experiences flocculation. The morphology and distribution of the gel are dense and uniform, and the gel has good cementation and filling effects. The macropores are obviously reduced, and the texture of the CST sample is very dense and uniform.

According to the above qualitative observation and analysis of the SEM images, as the curing age increases, the compactness of the microscopic pore structure of the CCT matrix increases. This is mainly due to the cementation and filling effects produced by the hydration products. During the hydration reaction, the amount and crystal morphology of the hydrated calcium silicate changes. This hydration product has a large surface energy and has a certain bonding ability, so that the edge-edge, edge-surface, and face-to-face contact (weak connection) between the tailing particles becomes a cemented joint with a certain cohesive force. This cemented joint strengthens the connection between the particles so that the discrete tailing particles form an integral structural unit. Simultaneously, the hydration product accumulates and precipitates on the surface of the tailing particles and between the interparticle pores, it coagulates and hardens, filling and refining the large pore structure, reducing the porosity and increasing the structure density. These two effects are interrelated and complement each other, which promotes the continuous evolution of the macroscopic physical and mechanical properties of the CCT. In this study, the increase in the mechanical strength and the decrease of permeability in the CCT are shown.

\subsection{Microscopic Pore Structure Evolution of the CCT with Curing Age}

From Equation (1), the relationship between the applied pressure and the pore size can be derived. The volume change of the mercury between each pressure step gives the pore size distribution (PSD) of the sample. The pore volume can be determined according to the amount of mercury intrusion. The cumulative intrusion and logarithmic differential intrusion curve can be obtained from the results of the MIP test; they all reflect the pore size distribution inside the sample in different forms, so they are called pore size distribution curves. From the latter representation, the logarithmic differential curve is obtained by differentiating the cumulative intrusion curve and is essentially a plot of $\mathrm{dV} / \mathrm{dlogd}$ 
against logd, as shown in Figure $6 \mathrm{~b}$. The pore size distribution curves provide pore structure parameter information for the total pore volume, critical pore size, and pore size distribution.

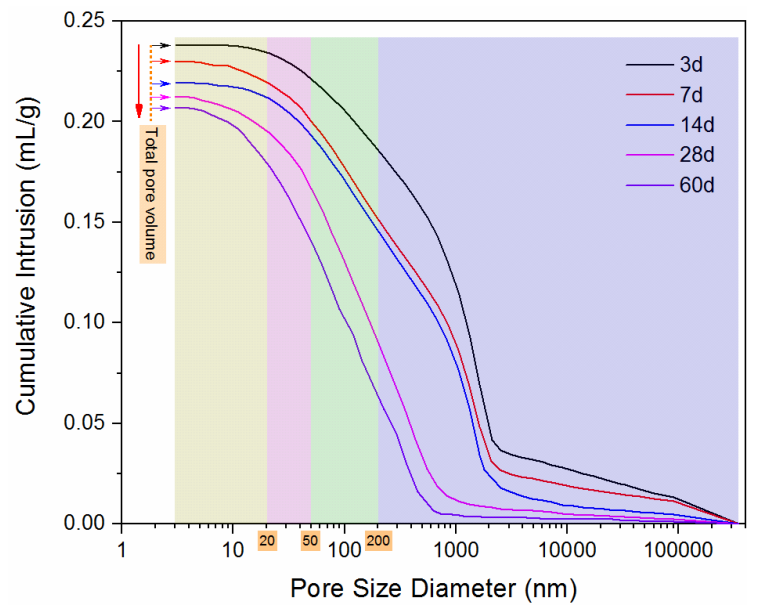

(a)

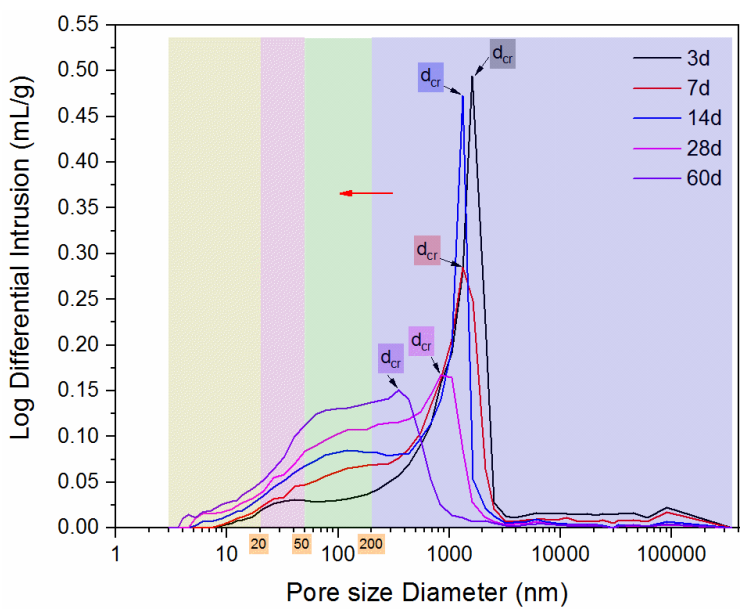

(b)

Figure 6. Pore size distribution of the CCT- 8 sample at different curing ages: (a) cumulative intrusion and (b) log differential intrusion (unit: $\mathrm{mL} / \mathrm{g}$ ).

Figure 6 shows the pore size distributions of the CCT- 8 sample at different curing ages between 3 and 60 days as determined by MIP tests.

In the cumulative intrusion curves, the total intrusion mercury volume corresponds to the point of the smallest pore diameter [58] or the highest intrusion pressure, giving the total pore volume of the test sample, presented in Figure 6a. As shown in Figure 6a, the general trend of total pore volume declines with increasing curing age. At a curing age of 3 days, the total pore volume was $0.2379 \mathrm{~mL} / \mathrm{g}$. After curing for 7, 14, 28, and 60 days, the total pore volume was reduced to $0.2298 \mathrm{~mL} / \mathrm{g}, 0.2191 \mathrm{~mL} / \mathrm{g}$, $0.2122 \mathrm{~mL} / \mathrm{g}$, and $0.2068 \mathrm{~mL} / \mathrm{g}$, respectively. This is because more hydration productions such as calcium silicate hydrate $(\mathrm{C}-\mathrm{S}-\mathrm{H})$, are produced with the progress of the cement hydration process (as discussed in Section 3.3). The precipitation of these hydrate and precipitate phases leads to the densification of the microstructure and a decrease in the connectivity between the pore spaces, which inevitably results in a lower total porosity. This indicates that as the curing age increases, the porosity of the consolidated body decreases and the compactness increases.

The critical pore size, $\mathrm{d}_{\mathrm{cr}}$, or maximum continuous pore size is also a frequently used parameter to characterize the micro-pore structure evolution. It corresponds to the highest point value on a logarithmic differential intrusion curve [59], or the onset of the steepest slope on the cumulative intrusion curve $[58,60,61]$, and was determined as an index of the pore structure connectivity. This point represents the grouping of the largest fraction of interconnected pores [62] or corresponds to the smallest pore size that creates connected paths through the sample [63]. The critical pore size has been proven to possess a strong relationship with the permeability properties of porous materials [64,65], representing the mean size of the pore entryways that allows the maximum percolation throughout the pore system. Furthermore, this parameter is most often used to study the effects of factors such as curing age, water-cement ratio, and curing conditions on the microstructure development $[60,66]$. The critical pore sizes of CCT- 8 samples at different curing ages are shown in Figure $6 \mathrm{~b}$. The results show that the critical pore size moves to a smaller pore diameter with increasing curing ages. At the curing age of 3 days, the critical pore size was1,614 nm. After curing for 7, 14, 28, and 60 days, the critical pore size is reduced to $1327 \mathrm{~nm}, 1315 \mathrm{~nm}, 833.9 \mathrm{~nm}$, and $349.8 \mathrm{~nm}$, respectively. This is attributed to the fact that as the cement hydration proceeds, more hydration products are produced and filled into the pore space, resulting in the movement of the peak to a smaller pore diameter [52]. This indicates that as the curing age increases, the pore structure is refined and the permeability of the CCT sample is reduced. 
From Figure $6 b$, we can also infer that as the curing age increases, the logarithmic differential intrusion curve shape also changes. The pore volume in the larger pore size range gradually decreases, while the pore volume in the smaller pore size range gradually increases; that is, the pore structure is continuously refined. In previous reports [67], the area under the logarithmic differential intrusion curve was used to analyze the micro-pore structure evolution. Some researchers classified the pore size distribution based on its effect on the macroscopic properties of porous materials. Wu et al. [68] divided the pore size (d) of concrete into four types: $d<20 \mathrm{~nm}$ (harmless pore), $d=20-50 \mathrm{~nm}$ (less harmful pore), $d=50-200 \mathrm{~nm}$ (harmful pore), $d>200 \mathrm{~nm}$ (more harmful pore) and proposed that increasing the pores below $50 \mathrm{~nm}$ and reducing the pores above $100 \mathrm{~nm}$ can improve the performance of the concrete. Mehta and Monteiro [69] separated the pore size (d) distribution of concrete into four portions: $\mathrm{d}>100 \mathrm{~nm}$ (more harmful pore), $\mathrm{d}=50-100 \mathrm{~nm}$ (harmful pore), $\mathrm{d}=4.5-50 \mathrm{~nm}$ (less harmful pore), $\mathrm{d}<4.5 \mathrm{~nm}$ (harmless pore), and noted that when $\mathrm{d}<50 \mathrm{~nm}$, the pore will exert less impact on the strength and permeability. The International Union of Pure and Applied Chemistry classification [70] classified the pore size (d) of a porous material into three categories: micropores ( $d<2 \mathrm{~nm}$ ), mesopores $(\mathrm{d}=2-50 \mathrm{~nm})$, and macropores $(\mathrm{d}>50 \mathrm{~nm})$. IO.M. Butt [71] separated the pore size $(\mathrm{d})$ distribution of concrete into four portions: macropore $(\mathrm{d}>1000 \mathrm{~nm})$, capillary pore $(\mathrm{d}=100-1000 \mathrm{~nm})$, transitional pore $(\mathrm{d}=10-100 \mathrm{~nm})$, and gel pore $(\mathrm{d}<10 \mathrm{~nm})$. In this study, the evolution law of the micro-pore structure of the CCT samples during the curing period is further quantitatively analyzed. Based on the logarithmic differential intrusion curve and the pore size classification method proposed by Wu et al. [68], the proportion of the pore size distribution that counted the total pore volume that ranged among $20 \mathrm{~nm}, 50 \mathrm{~nm}$, and $200 \mathrm{~nm}$ were calculated, and the results are described in Figure 7 . With increasing curing time, the proportion of the pore volume in the range of pore diameters larger than $200 \mathrm{~nm}$ gradually decreases. From $77 \%$ of the 3 day curing age reduced to $28 \%$ of the 60 day curing age, a $49 \%$ reduction was achieved. However, the proportion of the pore volume ranged from $\mathrm{d}<20 \mathrm{~nm}, \mathrm{~d}=20-50 \mathrm{~nm}$, and $\mathrm{d}=50-200 \mathrm{~nm}$ gradually increased as the curing age increased. However, there is a difference in the growth rate. The growth rates are increased by $8 \%, 14 \%$, and $26 \%$, respectively, corresponding to the pore size distribution range for $\mathrm{d}<20 \mathrm{~nm}, \mathrm{~d}=20-50 \mathrm{~nm}$, and $\mathrm{d}=50-200 \mathrm{~nm}$. After 60 days of curing, the majority of the pore diameters were less than $200 \mathrm{~nm}$. This further indicates that as the curing age increases, the pore structure inside the CCT samples was gradually refined, and the compactness increased.

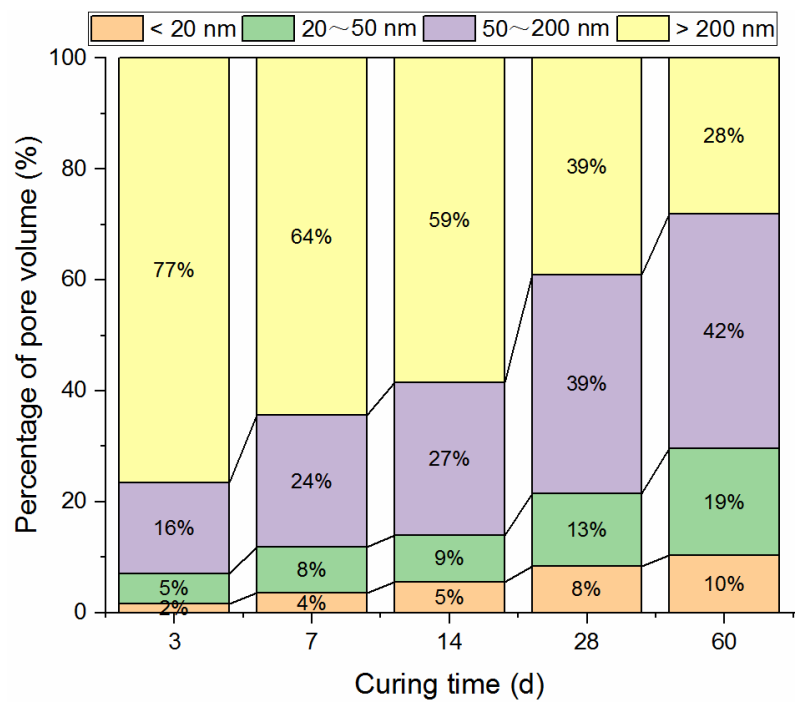

Figure 7. Evolution of the pore size distribution fractions with curing ages.

Combining the aforementioned strength and permeability (discussed in Sections 3.1 and 3.2) development with the curing age, it can be concluded that the pore diameter among the range of 
$\mathrm{d}=50-200 \mathrm{~nm}$ and $\mathrm{d}>200 \mathrm{~nm}$ obviously govern the strength and permeability characteristics of the CCT samples. The proportion of the substantial decrease for $d>200 \mathrm{~nm}$ and the significant increase of $\mathrm{d}=50-200 \mathrm{~nm}$ were consistent with the development trend of the strength and permeability.

\section{Conclusions}

This paper presents the macroscopic performance and microstructural properties evolution of CCT samples with increasing curing age. The tests performed include UCS tests, permeability tests, SEM observations, and MIP tests. During the curing period, the UCS, permeability, and microstructure markedly changed. Based on the results obtained within the limits of this study, the following conclusions and suggestions for future research can be summarized as follows:

(1) In general, the UCS of the CCT samples increases nonlinearly and the growth rate decreases with increasing curing age. This indicates that the structural stability of the consolidated pile gradually increases as the curing age increases. This will ensure the safety performance of a project to a certain extent. On a semilogarithmic scale, there is a linear relationship between the UCS and curing age, and the linear relationship can predict the UCS of the CCT samples in a reasonable manner.

(2) The CCT sample permeability decreased rapidly in a short period of curing age, i.e., between 0 and 7 days of curing age, gradually stabilized during the curing period of 7 to 28 days, and after 28 days curing reached a stable value. This permeability evolution trend helps to improve the environmental and corrosion resistance of the consolidated body. From the obtained experimental results, regression models were found to predict the permeability evolution of the CCT sample.

(3) The SEM observations reflect that with the hydration process, the morphology of the hydration products and microstructures changed significantly. SEM observations showed that strength, permeability, and the micro-pore structure evolution are related to increasing precipitation of the hydration product in the CCT samples.

(4) The pore structure evolution reported from the SEM signifies that as the curing age increases, the compactness of the CCT sample increases and the pore structure is refined, i.e., the CCT sample is refined. The total pore volume and the critical pore size decreased, and the proportion of pore volume for the large pores $(>200 \mathrm{~nm})$ decreased, whereas the small pore volume $(<200 \mathrm{~nm})$ increased. This is due to the growth of the hydration products filling the larger pores.

(5) Above all, the test results indicated that the cement consolidation applied to the surface tailings management is effective and the SEM observations and MIP tests allow us to better understand the evolution of the strength and permeability. The microscopic experimental results show that the strength and permeability are a macroscopic reflection of the microstructure. However, further studies are needed to quantitatively investigate the relationships between the macro behavior and microstructure properties during evolution.

Author Contributions: Conceive and design experiment, X.S. and Y.H.; experimental test, X.S.; data analysis and writing, X.S.; funding acquisition, Y.H. All authors have read and agreed to the published version of the manuscript.

Funding: This research was funded by the National Natural Science Foundation of China, grant number 51674263.

Acknowledgments: The authors are grateful to the National Natural Science Foundation of China (No. 51674263) for financial support.

Conflicts of Interest: The authors declare no conflict of interest.

\section{References}

1. InBrief. Mining's Contribution to Sustainable Development, Trends in the mining and metals industry. In Proceedings of the International Council on Mining and Metals, London, UK, 26 October 2012.

2. Lottermoser, B.G. Mine Wastes: Characterization, Treatment and Environmental Impacts, 3th ed.; Springer: New York, NY, USA, 2010.

3. Xue, Y.Z.; Wang, H.J. National Mineral Resources Saving and Comprehensive Utilization Report; Geological Publishing House: Beijing, China, 2014. 
4. Hudson-Edwards, K.A.; Jamieson, H.E.; Lottermoser, B.G. Mine wastes: Past, present, future. Elements 2011, 7, 375-380. [CrossRef]

5. Zou, D.H.; Sahito, W. Suitability of mine tailings for shotcrete as a ground support. Can. J. Civ. Eng. 2011, 31, 632-636. [CrossRef]

6. Kitula, A.G.N. The environmental and socio-economic impacts of mining on local livelihoods in Tanzania: A case study of Geita District. J. Clean. Prod. 2006, 14, 405-414. [CrossRef]

7. Bruno, B. Colloquium 2004: Hydrogeotechnical properties of hard rock tailings from metal mines and emerging geoenvironmental disposal approaches. Can. Geotech. J. 2007, 44, 1019-1052. [CrossRef]

8. Zhang, J.; Li, M.; Taheri, A.; Zhang, W.; Wu, Z.; Song, W. Properties and application of backfill materials in coal mines in china. Minerals 2019, 9, 53. [CrossRef]

9. Belem, T.; Benzaazoua, M. Design and application of underground mine paste backfill technology. Geotech. Geol. Eng. 2008, 26, 147-174. [CrossRef]

10. Benzaazoua, M.; Ouellet, J.; Servant, S.; Newman, P.; Verburg, R. Cementitious backfill with high sulfur content: Physical, chemical and mineralogical characterization. Cem. Concr. Res. 1999, 29, 719-725. [CrossRef]

11. Jantzer, I.; Knutsson, S. Critical Gradients for Tailings Dam Design; Australian Centre for Geomechanics: Crawley, Australia, 2010.

12. Aubertin, M.; Bussière, B.; Bernier, L. Environnement et Gestion des Rejets Miniers—Manual on CD-ROM; Presses internationales Polytechnique: Montreal, QC, Canada, 2002.

13. Macklin, M.G.; Brewer, P.A.; Balteanu, D.; Coulthard, T.J.; Driga, B.; Howard, A.J. The long term fate and environmental significance of contaminant metals released by the january and march 2000 mining tailings dam failures in maramureş county, upper tisa basin, romania. Appl. Geochem. 2003, 18, 241-257. [CrossRef]

14. Berghe, J.F.V.; Ballard, J.; Wintgens, J.; List, B. Geotechnical risks related to tailings dam operations. In Proceedings of the Tailings and Mine Waste 2011, Vancouver, BC, Canada, 6-9 November 2011.

15. Carmo, F.F.D.; Kamino, L.H.Y.; Junior, R.T.; Campos, I.C.D.; Carmo, F.F.D.; Silvino, G. Fundão tailings dam failures: The environment tragedy of the largest technological disaster of brazilian mining in global context. Perspect. Ecol. Conser. 2017, 15, 145-151. [CrossRef]

16. Ke, X.; Zhou, X.; Wang, X.; Wang, T.; Hou, H.; Zhou, M. Effect of tailings fineness on the pore structure development of cemented paste backfill. Constr. Build. Mater. 2016, 126, 345-350. [CrossRef]

17. Fernandes, G.W.; Goulart, F.F.; Ranieri, B.D.; Coelho, M.S.; Dales, K.; Boesche, N. Deep into the mud: Ecological and socio-economic impacts of the dam breach in mariana, brazil. Nat. Conserv. 2016, 14, $35-45$. [CrossRef]

18. Zhang, L.; He, G.Z.; Mol, A.P.J. China's new environmental protection law: A game changer? Environ. Dev. 2015, 13, 1-3. [CrossRef]

19. Alakangas, L.; Dagli, D.; Knutsson, S. Literature Review on Potential Geochemical and Geotechnical Effects of Adopting Paste Technology Under Cold Climate Conditions; Division of Mining and Geotechnical Engineering-Luleå University of Technology: Luleå, Sweden, 2013.

20. Fall, M.; Adrien, D.; Célestin, J.C.; Pokharel, M.; Touré, M. Saturated hydraulic conductivity of cemented paste backfill. Miner. Eng. 2009, 22, 1307-1317. [CrossRef]

21. Hou, Y.B.; Tang, J.; Wei, S.X. Research on tailings' cementation and discharging technology. Metal Mine 2011, 40,59-62.

22. Zhao, Y.; Soltani, A.; Taheri, A.; Karakus, M.; Deng, A. Application of slag-cement and fly ash for strength development in cemented paste backfills. Minerals 2018, 9, 22. [CrossRef]

23. Zhang, J.; Deng, H.; Taheri, A.; Deng, J.; Ke, B. Effects of superplasticizer on the hydration, consistency, and strength development of cemented paste backfill. Minerals 2018, 8, 381. [CrossRef]

24. Das, R.; Choudhury, I. Waste management in mining industry. Indian J. Sci. Res. 2013, 4, 139-142.

25. Benzaazoua, M.; Bussiere, B.; Kongolo, M.; McLaughlin, J.; Marion, P. Environmental desul-phurization of four Canadian mine tailings using froth flotation. Int. J. Miner. Process. 2000, 60, 57-74. [CrossRef]

26. Dagenais, A.; Aubertin, M.; Bussière, B.; Martin, V. Large scale applications of covers with capillary barrier effects to control the production of acid mine drainage. In Proceedings of the Post-Mining, Nancy, France, 16-17 November 2005.

27. Federico, A.; Vitone, C.; Murianni, A. On the mechanical behaviour of dredged submarine clayey sediments stabilized with lime or cement. Can. Geotech. J. 2015, 52, 2030-2040. [CrossRef] 
28. Kumar, R.; Bhattacharjee, B. Porosity, pore size distribution and in situ strength of concrete. Cem. Concr. Res. 2003, 33, 155-164. [CrossRef]

29. Cao, S.; Yilmaz, E.; Song, W. Evaluation of viscosity, strength and microstructural properties of cemented tailings backfill. Minerals 2018, 8, 352. [CrossRef]

30. Matusinovic, T.; Sipusic, J.; Vrbos, N. Porosity-strength relation in calcium aluminate cement pastes. Cem. Concr. Res. 2003, 33, 1801-1806. [CrossRef]

31. Ozturk, A.U.; Baradan, B. A comparison study of porosity and compressive strength mathematical models with image analysis. Comp. Mater. Sci. 2008, 43, 974-979. [CrossRef]

32. Zhou, N.; Ma, H.; Ouyang, S.; Germain, D.; Hou, T. Influential factors in transportation and mechanical properties of aeolian sand-based cemented filling material. Minerals 2019, 9, 116. [CrossRef]

33. Rong, H.; Zhou, M.; Hou, H. Pore Structure Evolution and Its Effect on Strength Development of Sulfate-Containing Cemented Paste Backfill. Minerals 2017, 7, 8. [CrossRef]

34. Cui, L.; Cahyadi, J.H. Permeability and pore structure of opc paste. Cem. Concr. Res. 2001, 31, $277-282$. [CrossRef]

35. Atzeni, C.; Pia, G.; Sanna, U. A geometrical fractal model for the porosity and permeability of hydraulic cement pastes. Constr. Build. Mater. 2010, 24, 1843-1847. [CrossRef]

36. Yang, Z.Q.; Li, A.X.; Zhang, R.S. The effect of w/c ratio and curing temperature on the permeability of hardened cement paste. J. Shandong Inst. of Min. Technol. 2002, 11, 575-579.

37. Common Portland Cement; Chinese Standard: GB 175-2007; China Building Material Federation: Beijing, China, 2007.

38. Béket Dalcé, J.; Li, L.; Yang, P. Experimental Study of Uniaxial Compressive Strength (UCS) Distribution of Hydraulic Backfill Associated with Segregation. Minerals 2019, 9, 147. [CrossRef]

39. Al-Rawas, A.A.; Mcgown, A. Microstructure of Omani expansive soils. Can. Geotech. J. 1999, 36, $272-290$. [CrossRef]

40. Zhang, T.W.; Yue, X.B.; Deng, Y.F.; Zhang, D.W.; Liu, S.Y. Mechanical behaviour and micro-structure of cement-stabilised marine clay with a metakaolin agent. Constr. Build. Mater. 2014, 73, 51-57. [CrossRef]

41. Belem, T.; Bussière, B.; Benzaazoua, M. The effect of microstructural evolution on the physical properties of paste backfill. In Proceedings of the Tailings and Mine Waste, Fort Collins, CO, USA, 1 January 2001.

42. Deschamps, T.; Benzaazoua, M.; Bussière, B.; Aubertin, M.; Belem, T. Microstructural and geochemical evolution of paste tailings in surface disposal conditions. Miner. Eng. 2008, 21, 341-353. [CrossRef]

43. Koohestani, B.; Koubaa, A.; Belem, T.; Bruno, B.; Bouzahzah, H. Experimental investigation of mechanical and microstructural properties of cemented paste backfill containing maple-wood filler. Constr. Build. Mater. 2016, 121, 222-228. [CrossRef]

44. Feldman, R.F. Significance of porosity measurements on blended cement performance. In Proceedings of the First International Conference on the Use of Fly Ash, Silica Fume, Slag and Other Mineral Byproducts in Concrete, Montebello, Quebec, QC, Canada, 31 July-5 August 1983.

45. Ouellet, S.; Bussière, B.; Benzaazoua, M.; Aubertin, M.; Belem, T. Effect of binder type and mixing water chemistry on microstructural evolution of cemented paste backfill. In Proceedings of the 57th Canadian Geotechnical Conference and 5th Joint CGS-LAH Conference, Quebec, QC, Canada, 24-27 October 2004.

46. Chen, X.D.; Wu, S.X. Influence of water-to-cement ratio and curing period on pore structure of cement mortar. Constr. Build. Mater. 2013, 38, 804-812. [CrossRef]

47. Washburn, E.W. Note on a Method of Determining the Distribution of Pore Sizes in a Porous Material. Phys. E. W. Washburn 1921, 7, 115-116. [CrossRef] [PubMed]

48. Zhou, J.; Ye, G.; Breugel, K.V. Characterization of pore structure in cementbased materials using pressurization-depressurization cycling mercury intrusion porosimetry (PDC-MIP). Cem. Concr. Res. 2010, 40, 1120-1128. [CrossRef]

49. Dhandapani, Y.; Santhanam, M. Assessment of pore structure evolution in the limestone calcined clay cementitious system and its implications for performance. Cem. Concr. Comp. 2017, 84, 36-47. [CrossRef]

50. Pore Size Distribution and Porosity of Solid Materials by Mercury Porosimetry and Gas Adsorption-Part1: Mercury Porosimetry; Chinese Standard: GB/T 21650.1-2008.; National Technical Committee for Standardization of Sieve Screening and Particle Sorting Methods: Beijing, China, 2008.

51. Chindaprasirt, P.; Jaturapitakkul, C.; Sinsiri, T. Effect of fly ash fineness on compressive strength and pore size of blended cement paste. Cem. Concr. Comp. 2005, 27, 425-428. [CrossRef] 
52. Yu, Z.; Ye, G. The pore structure of cement paste blended with fly ash. Constr. Build. Mater. 2013, 45, 30-35. [CrossRef]

53. Ye, G. Experimental study and numerical simulation of the development of the microstructure and permeability of cementitious materials. J. Colloid Interface Sci. 2003, 262, 149-161. [CrossRef]

54. Horpibulsuk, S.; Nagaraj, T.S.; Miura, N. Assessment of strength development in cement-admixed high water content clays with abrams' law as a basis. Géotechnique 2003, 53, 439-444. [CrossRef]

55. Fridjonsson, E.O.; Hasan, A.; Fourie, A.B.; Johns, M.L. Pore structure in a gold mine cemented paste backfill. Miner. Eng. 2013, 53, 144-151. [CrossRef]

56. Fall, M.; Samb, S.S. Effect of high temperature on strength and microstructural properties of cemented paste backfill. Fire. Saf. J. 2009, 44, 642-651. [CrossRef]

57. Kong, X.M.; Lu, Z.C.; Zhang, C.Y. Development on understanding cement hydration mechanism and effects of chemical admixtures on cement hydration. J. Chin. Ceram. Soc. 2017, 45, 274-281. [CrossRef]

58. Aligizaki, K.K. Pore Structure of Cement-Based Materials: Testing, Interpretation and Requirement; Modern Concrete Technology Series: New York, NY, USA, 2006; Volume 12.

59. Cook, R.A.; Hover, K.C. Mercury porosimetry of hardened cement pastes. Cem. Concr. Res. 1999, 29 , 933-943. [CrossRef]

60. Yilmaz, E.; Belem, T.; Bussière, B.; Benzaazoua, M. Relationships between microstructural properties and compressive strength of consolidated and unconsolidated cemented paste backfills. Cem. Concr. Comp. 2011, 33, 702-715. [CrossRef]

61. Ma, H.Y.; Xu, B.W.; Liu, J.; Pei, H.P.; Li, Z.J. Effects of water content, magnesia-tophosphate molar ratio and age on pore structure, strength and permeability of magnesium potassium phosphate cement paste. Mater. Des. 2014, 64, 497-502. [CrossRef]

62. Halamickova, P.; Detwiler, R.J.; Bentz, D.P.; Garboczi, E.J. Water permeability and chloride ion diffusion in Portland cement mortars: Relationship to sand content and critical pore diameter. Cem. Concr. Res. 1995, 25, 790-802. [CrossRef]

63. Katz, A.J.; Thompson, A.H. Quantitative prediction of permeability in porous rock. Phys. Rev. B 1986, 34, 8179-8181. [CrossRef]

64. Hu, J.; Stroeven, P. Proper characterisation of pore size distribution in cementitious materials. In Proceedings of the International Symposium on Environmental Ecology and Technology of Concrete (EETC 2005), Urumqi, China, 6-8 June 2005; pp. 479-485.

65. Yang, C.C. On the relationship between pore structure and chloride diffusivity from accelerated chloride migration test in cement-based materials. Cem. Concr. Res. 2006, 36, 1304-1311. [CrossRef]

66. Ghirian, A.; Fall, M. Coupled thermo-hydro-mechanical-chemical behaviour of cemented paste backfill in column experiments: Part I: Physical, hydraulic and thermal processes and characteristics. Eng. Geol. 2013, 164, 195-207. [CrossRef]

67. Ghirian, A.; Fall, M. Coupled thermo-hydro-mechanical-chemical behaviour of cemented paste backfill in column experiments: Part II: Mechanical, chemical and microstructural processes and characteristics. Eng. Geol. 2014, 170, 11-23. [CrossRef]

68. Liu, L.; Fang, Z.Y.; Qi, C.C.; Zhang, B.; Guo, L.J.; Song, K.-I. Experimental investigation on the relationship between pore characteristics and unconfined compressive strength of cemented paste backfill. Constr. Build. Mater. 2018, 179, 254-264. [CrossRef]

69. Mehta, P.K.; Monteiro, P.J.M. Education, Concrete: Microstructure, Properties, and Materials; McGraw-Hill: New York, NY, USA, 2006.

70. IUPAC. Manual of symbols and terminology. Appendix 2, part 1: Colloid and surface chemistry. Pure Appl. Chem. 1972, 31, 578.

71. Shen, A.Q. Cement and Cement Concrete; China Communications Press: Beijing, China, 2004.

(C) 2019 by the authors. Licensee MDPI, Basel, Switzerland. This article is an open access article distributed under the terms and conditions of the Creative Commons Attribution (CC BY) license (http://creativecommons.org/licenses/by/4.0/). 